\title{
Geographical influence of heat stress on milk production of Holstein dairy cattle on pasture in South Africa under current and future climatic conditions
}

\author{
R. Williams ${ }^{1 \#}$, M. M. Scholtz ${ }^{2,3}$ \& F. W. C. Neser ${ }^{3}$ \\ ${ }^{1}$ ARC Onderstepoort Veterinary Institute, Private Bag X05, Onderstepoort 0110, South Africa; ${ }^{2}$ ARC-Animal Production \\ Institute, Private Bag X2, Irene, 0062, South Africa; ${ }^{3}$ Department of Animal, Wildlife and Grassland Sciences, University \\ of the Free State, PO Box 339, Bloemfontein 9300, South Africa
}

(Received 15 July 2015; Accepted 30 September 2016; First published online 2 December 2016)

Copyright resides with the authors in terms of the Creative Commons Attribution 2.5 South African Licence. See:
http://creativecommons.org/licenses/by/2.5/za/

\begin{abstract}
Heat stress, as a consequence of global warming, can have a profound effect on dairy cattle in South Africa. In this paper, current milk production data of Holstein dairy herds on pasture in South Africa, together with climate variables related to heat stress, were used to model and identify geographical areas for optimal milk production under current and future climatic conditions. To model the influence of heat stress on milk production of Holstein dairy herds on pasture in South Africa, the maximum entropy (Maxent) modelling technique was used in a novel approach to model and map optimal milk-producing areas. Geographical locations of farms with top milk-producing Holstein herds on pasture were used as presence-only data points. Only three of a possible eight climate variables that made significant contributions to the model were included, namely evaporation rate, relative humidity and mean annual temperature. The modelling technique showed good capability to capture the geographical influence of heat stress on milk production of Holstein dairy cattle and to reconstruct this relationship in sites where no data were available. The method performed well with low test omission rates, an area under curve (AUC) value of 0.929 , and mean training data predictive rate of $0.66(S D=0.13)$. The modelled map indicated optimal milk production areas in the eastern parts of South Africa, which correlates well with the geographical influence of heat stress as represented by the temperature humidity index for the country. Future climate change projections (2046-2065) were used to predict optimal milk-producing areas for the future, indicating progressive shrinking of currently suitable areas and a geographical shift towards the southern parts of the east coast of South Africa. Possible longterm viable alternatives are suggested, including changes in nutrition and replacing existing breeds with more heat tolerant genotypes.
\end{abstract}

Keywords: climate change, climate variables, Maxent modelling, temperature-humidity index

\#Corresponding author: WilliamsR@arc.agric.za

\section{Introduction}

There are 2700 dairy farmers in South Africa, with 16200 employees and 89000 dependants. The total number of dairy cattle in the commercial sector is estimated to be 1.37 million and the provinces in which the most dairy cattle are found are the Western Cape, Eastern Cape and KwaZulu-Natal, with 323 000, 348000 and 268000 dairy cattle, respectively (Meissner et al., 2013a).

In South Africa, total mixed ration (TMR) and pasture production systems or a combination of these are followed, depending on the region (Scholtz et al., 2014). Currently between $65 \%$ and $75 \%$ of milk production is based on pasture (Meissner, personal communication). However, many of these pasture-based systems increasingly incorporate additional feeding such as concentrates or forage crops as hay or silage (Muller \& Scholtz, 2014). For dairy cattle, the effect of climate change is predicted to be more severe on pasture-based systems where an increase in temperature and a decrease in precipitation are projected (Rust \& Rust, 2013).

Current climate projections indicate an increase in average temperature of $1.5{ }^{\circ} \mathrm{C}$ to $2{ }^{\circ} \mathrm{C}$. It will become generally drier in the southern African region, except for the central parts of the country and the Eastern Cape, where higher rainfall is predicted. The anticipated decrease in rainfall is predicted for the eastern parts of Limpopo and Mpumalanga, and the south-western and south coast of the Cape (Meissner et al., 2013b). These higher temperatures may result in heat stress among livestock, which cannot be counteracted by behaviour adaptation. High producing dairy cows may be particularly vulnerable (West, 
2003; Bernabucci et al., 2010). It was therefore postulated by Meissner et al. (2013b) that cows in the interior of the country may be affected more frequently by heat stress, whereas those on the pasture systems of the south-eastern seaboard may not be affected significantly. It is therefore important to understand the effect of climate change on milk production in South Africa.

Heat stress has a profound influence on milk production of dairy cattle (Kadzere et al., 2002). It can occur when the ambient temperature exceeds $25 \stackrel{\circ}{\circ}$, with concurrent high humidity, low airflow and direct sunlight (Hahn, 1999; Berman et al., 1985), causing higher concentrations of water vapour in the atmosphere, which renders evaporative heat loss in cattle less effective. In an attempt to reduce heat stress and to maintain homeothermy, cattle increase respiration rates, decrease feed intake, and increase water intake (Silva, 2000). This is accompanied by increased blood flow to the skin surface, reduced metabolic rate, and altered water metabolism (West, 1999). Consequently, in dairy cattle, more energy would be utilized for cooling down and less for milk production.

Since there are significant differences in climatological relative humidity and diurnal temperature range across South Africa, milk loss of dairy cattle owing to heat stress varies not only seasonally, but also geographically (Du Preez et al., 1990a). This is particularly relevant to Holstein dairy herds on pasture, which are concentrated in the eastern and southern parts of the country. In addition, South Africa is one of the regions of the world that will be most vulnerable to future climate variability and change (Scholtz et al., 2013; Schulze, 2010). As hot and humid climatic conditions become more extreme, the negative impact on milk production will become more severe. This impact will have a socio-economic effect, since towns in the nonmetropolitan areas are dependent largely on the commercial farming activities of the district (Meissner et al., 2013a).

The purpose of this paper is therefore to use current milk production data of Holstein dairy herds on pasture in South Africa, together with climate variables related to heat stress, to model geographical areas for optimal milk production under current and future climatic conditions.

\section{Materials and Methods}

The SA Holstein Breeders' Society provided milk production data for all Holstein dairy herds that are kept on pasture $(n=37)$. The herds were ranked from high to low according to mean corrected 305-day milk production. Of these, the top third $(n=13)$ were selected for modelling geographical areas for optimal milk production. Figure 1 shows the geographical distribution of all dairy farms where Holstein cattle are kept on pasture $(n=37)$ for which milk production data were available, and the top 13 milk-producing herds selected for this study.

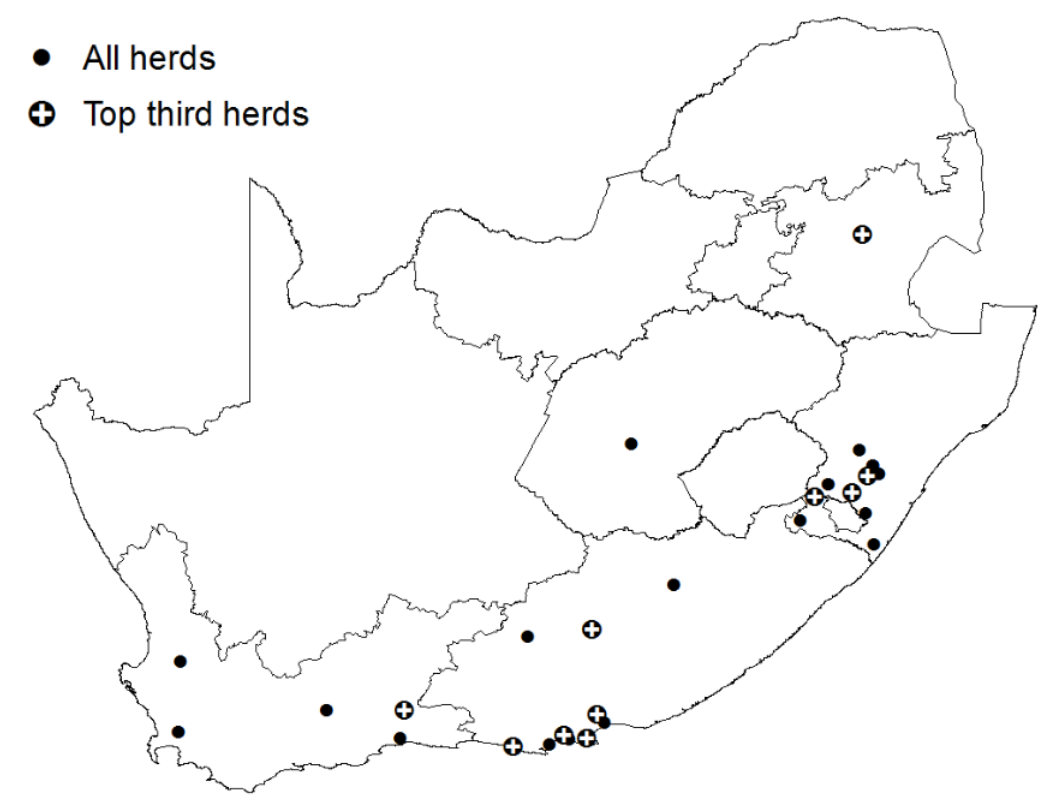

Figure 1 Map of geographical locations of Holstein dairy herds on pasture $(n=37)$ with top-producing herds $(n=13)$ superimposed 
In Table 1, a comparison is presented of the descriptive statistics of all Holstein herds on pasture and the top third of the herds used in this study.

Table 1 Descriptive statistics of all Holstein dairy herds on pasture compared with the top third milkproducing Holstein herds on pasture

\begin{tabular}{lccccc}
\hline & $\begin{array}{c}\text { Number of } \\
\text { herds }\end{array}$ & $\begin{array}{c}\text { Average milk } \\
\text { production }(\mathrm{kg})\end{array}$ & $\begin{array}{c}\text { Minimum } \\
(\mathrm{kg})\end{array}$ & $\begin{array}{c}\text { Maximum } \\
(\mathrm{kg})\end{array}$ & $\begin{array}{c}\text { Standard } \\
\text { deviation }(\mathrm{kg})\end{array}$ \\
\hline All herds & 37 & 6650 & 5011 & 10357 & 1184 \\
Top third herds & 13 & 7820 & 6589 & 10357 & 1037 \\
\hline
\end{tabular}

Maximum entropy (Maxent) is a machine learning modelling technique for making predictions or inferences from incomplete information. It is used in diverse areas such as astronomy, statistical physics and signal processing (Phillips et al., 2006). Recently it has been widely used as a general approach to modelling species distribution with presence-only (PO) data points. It estimates the less constrained distribution of training points compared with random background locations, with environmental data layers defining constraints (Baldwin, 2009). The results illustrate how well the model fits the location data compared with random distribution (Phillips et al., 2004; Phillips et al., 2006). To use Maxent to model suitable (optimal) geographical areas for milk production in Holstein herds on pasture, geographical locations of the farms with top milk-producing Holstein herds were used as PO data points.

The critical step in formulating the model was to define a set of variables that represent the heat stress factors that constrain geographical areas for optimal milk production. Based on the temperature-humidity index (Du Preez et al., 1990b; Du Preez et al., 1990c; Salem \& Bouraoui, 2009), a widely used parameter that is indicative of heat stress in animals, these eight potentially relevant climate variables were considered for the model: solar radiation $\left(\mathrm{MJ} \cdot \mathrm{m}^{-2} \cdot \mathrm{day}^{-1}\right)$, mean relative humidity $(\%)$, mean annual temperature $\left({ }^{\circ} \mathrm{C}\right)$, temperature range $\left({ }^{\circ} \mathrm{C}\right)\left(\mathrm{T}_{\mathrm{max}}-\mathrm{T}_{\mathrm{min}}\right)$, extremes of maximum temperature (number of incidences), summer heat units (sum of degree days above a $13^{\circ} \mathrm{C}$ threshold), potential evaporation $(\mathrm{mm})$, and mean annual precipitation $(\mathrm{mm})$ (Schulze, 1997). Digital images of climate variables were converted with ArcGIS 9.3 (ESRI) to $1 \times 1 \mathrm{~km}$ spatial resolution grids covering the whole of South Africa.

The model was implemented with freeware Maxent developed by Phillips et al. (2005), in which 'species occurrence' training, test files and variable data layers are automatically recognized by the application. All default parameter values were used, except for the regulation value, which was set to an average value of 3 , on a scale of 1 to 5 , to reduce over-fitting of the model. The jack-knife test of variable importance was used to evaluate the relative contribution of each variable to the model, together with analysis of response curves, showing the response of each variable to presence probability. By a process of elimination, only three variables were selected for the final model, namely evaporation rate, relative humidity and mean annual temperature, showing percentage contributions of $58.5 \%, 37.6 \%$ and $3.9 \%$, respectively, to the model. The logistic output format of Maxent was selected, producing a continuous value between 0 and 100; each resulting raster pixel contained a value that reflected the predictive condition for that pixel. The final results in ASCl file format were exported into ArcGIS 9.3 (ESRI, 2014) to produce a suitability map.

Receiver operating characteristic (ROC) curve analysis, a threshold-independent method for comparing model performance, is widely used in clinical medicine (Zweig \& Campbell, 1993). In Maxent, the AUC determines whether a prediction is better than random for any possible presence threshold, and varies between 0.5 , when the result is equal to random, and 1 , when the result is significantly better than random (Phillips et al., 2006). The Maxent algorithm calculates false negatives (omission error), a prediction error for training and test data (Ward, 2007) which indicates the percentage of test localities that fall into pixels that are not predicted as suitable. It should be low for good model performance (Phillips et al., 2006). Fifty replicates of the model were subsequently analysed to find the model with the highest AUC and the lowest training and test omission rates.

To model the geographical impact of heat stress caused by future climate change on the milk production of Holstein dairy cattle on pasture, projections of the climate variables from the Atlas of climate change and the South African agricultural sector: A 2010 perspective (Schulze, 2010) were used in Maxent with PO data points of top-producing Holstein herds. Future global climate scenarios were downscaled by the Climate Systems Analysis Group (CSAG) at the University of Cape Town to point scale and based on the 
A2 emissions scenario defined by the Intergovernmental Panel on Climate Change (IPCC)[in full] Special Report on Emission Scenarios (Nakićenović et al., 2000).

\section{Results and Discussion}

Figure 2 shows the modelled suitability of geographical areas in South Africa for optimal milk production with Holstein dairy cattle on pasture.

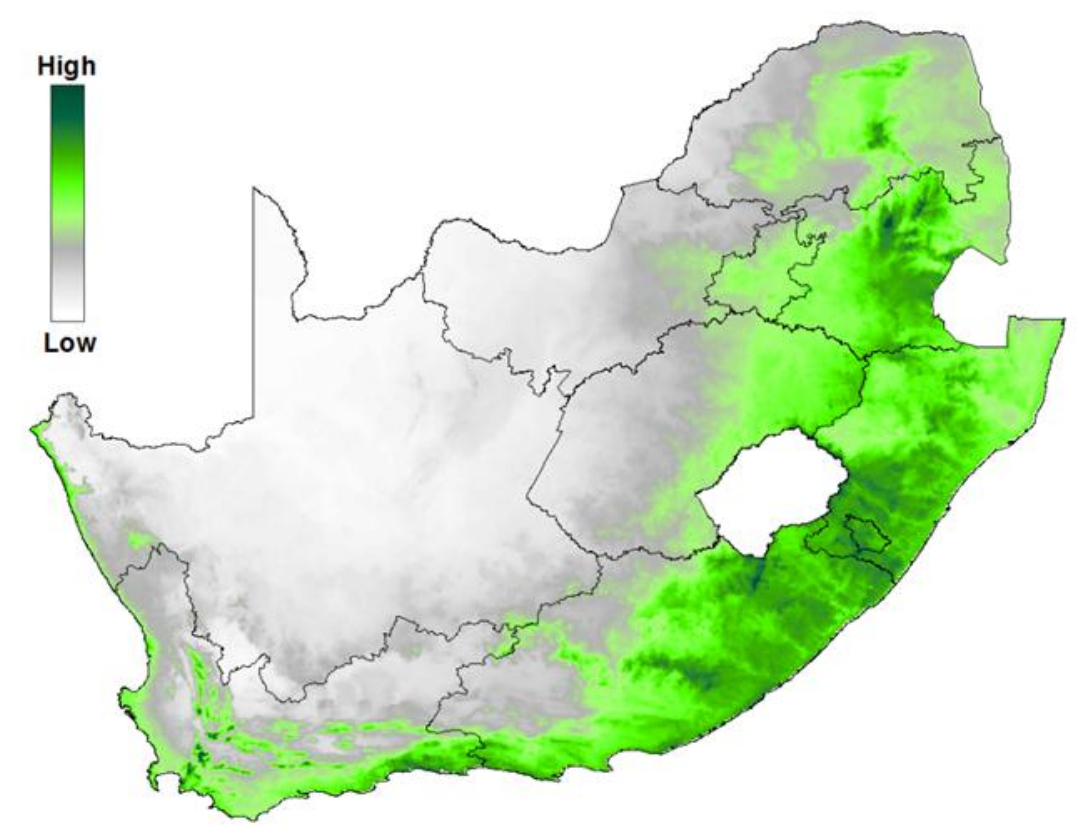

Figure 2 Map of the modelled suitability of geographical areas in South Africa for optimal milk production of Holstein dairy cattle on pasture

The resultant model, which produced the suitability map in Figure 2, is a novel use of the Maxent modelling technique, which does not allow for comparison with similar models. However, it shows that the modelling technique has good capability to capture the geographical influence of heat stress on milk production of Holstein dairy herds on pasture and to reconstruct this relationship, even in sites where no data were available. The method also performed well in predicting potential suitable areas for optimal milk production. Test omission rates were null at minimum training presence threshold for training and test datasets (rate $=0.000$ ), as well as at the 10 percentile training presence threshold. This proves that the model performed well in predicting potential suitable areas for optimal milk production. The model shows an AUC value of 0.929 , which generally proves good model performance, although the AUC could be somewhat overestimated in this case because the training data are spatially aggregated (Phillips \& Dudík, 2008). The mean training data predictive rate is $0.66(S D=0.13)$ and the model's predictive capacity therefore seems to be good, based on the correctly predicted calibration points. Moreover, the model's rendering of the geographical influence of heat stress on milk production correlates well with the geographical representation of the temperature humidity index for the country.

It is anticipated that potential rising temperatures caused by future climate change will have a negative impact on milk production in currently suitable milk-producing areas in South Africa. Figure 3 shows the projected change in mean temperature for January for the future (2046-2065) relative to the historical longterm mean.

Figure 4 shows the modelled suitability map of geographical areas in South Africa for optimal milk production with Holstein dairy cattle on pasture using projected climate change data (2046-2065). It indicates that the predicted impact of heat stress would cause a geographical shift of optimal milk production areas towards the southern parts of the east coast. This is in support of Meissner et al.'s (2013b) postulation that dairy cows on pasture systems of the south-eastern seaboard may be less affected by heat stress. 


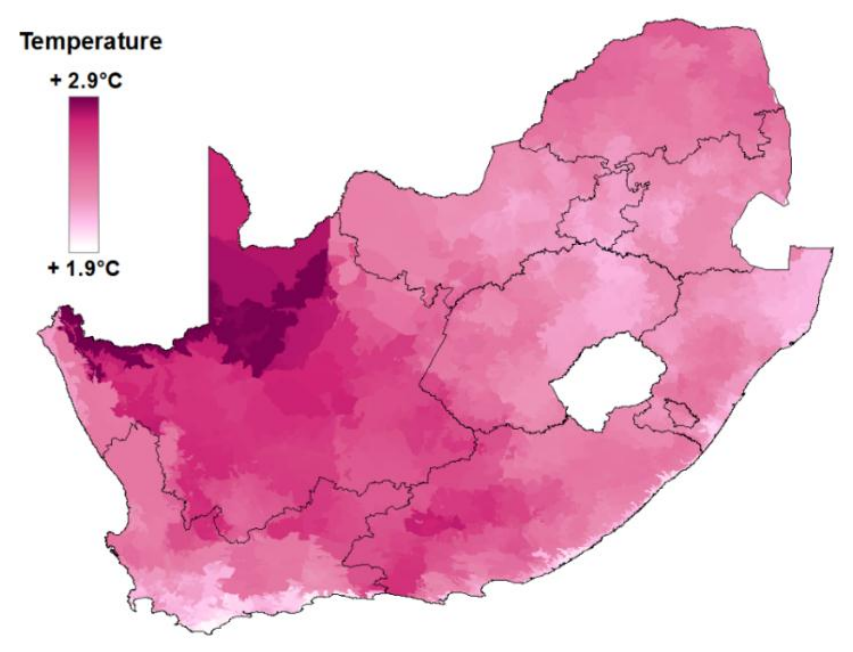

Figure 3 Projected change in the mean temperature for January for the future (2046-2065) relative to the historical long-term mean

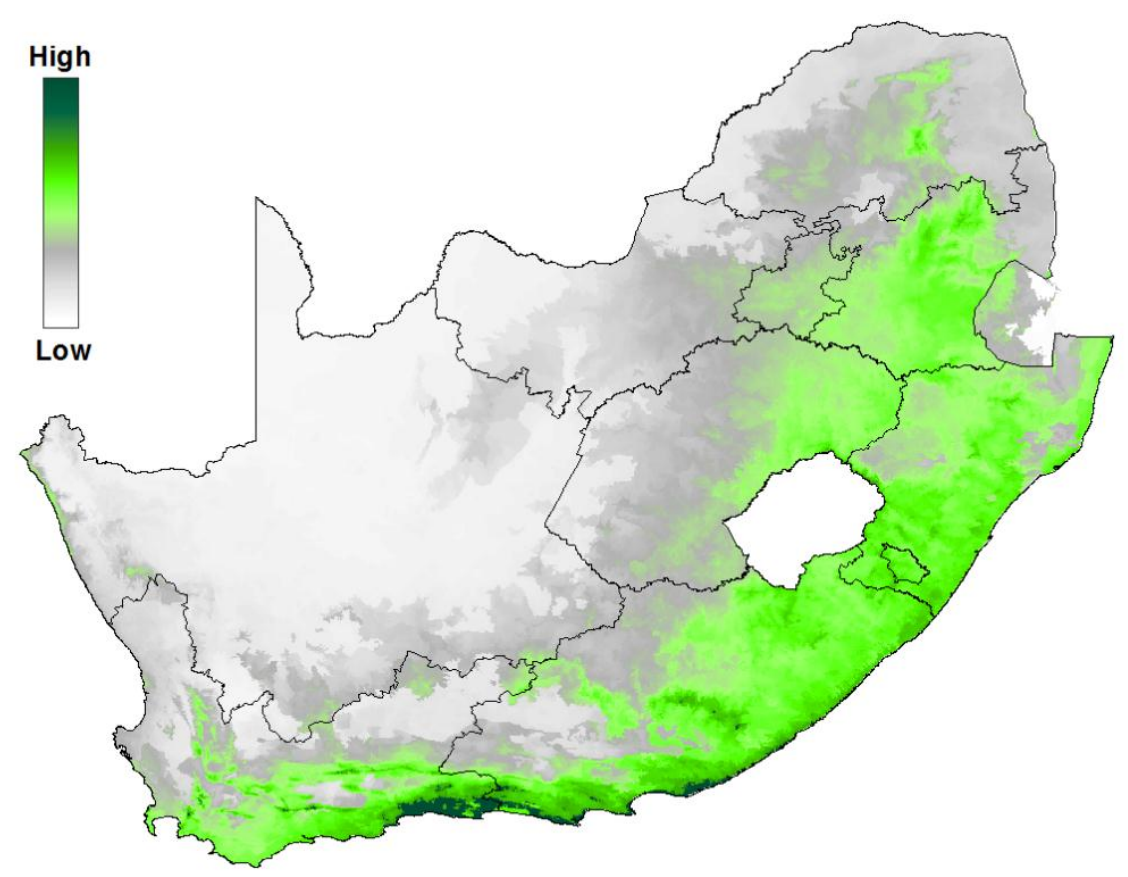

Figure 4 Map of modelled suitability of geographical areas in South Africa for optimal milk production with Holstein dairy cattle on pasture using projected climate-change data (2046-2065)

\section{Recommendations}

Possible mitigation strategies for heat stress include management and nutritional interventions, and breeding for resilience to the changing climatic conditions. Management approaches to reduce the effects of increased temperature may include mechanical cooling, such as forced ventilation, water sprayers and shading. However, these are difficult to apply to dairy cattle on pasture, and offer limited relief in the short 
term. Where temperatures rise above the upper critical temperature, which may occur more frequently as a result of the climate-change predictions in this article, long-term viable alternatives such as changing nutrition and replacing breeds with more heat tolerant strains are necessary.

Selection of dairy cattle that adapt better to the production environment is essential to enable the sustainability of dairy production systems in hotter climates. An issue of concern is whether there is enough genetic variation in traditional dairy breeds to allow for selection of individuals that are adapted to such changing climatic conditions. A breed of particular concern is the Holstein-Friesian, in which the global effective population size is estimated to be only 75 (McParland et al., 2007). A solution could be the utilization of crossbreeding between dairy breeds or even the infusion of adapted Sanga and Zebu breeds. Although milk production might be lower, heterosis would enhance the adaptability of the crossbred animals.

The ongoing specialization in milk and meat production has been questioned by Zehetmeier et al. (2012), who proposed the use of dual-purpose breeds as purebreds or in a crossbreeding programme with specialist dairy breeds as an alternative. Tropically adapted Zebu dairy cattle are already being utilized in tropical countries such as Brazil. Muller et al. (2013a) report that the milk yield of crossbred cows was $14 \%$ higher than that of purebred Jersey cows, whereas the comparative increase in milk production was smaller when Holstein cows were crossed with Fleckvieh, however, the fertility and milk composition of the crossbred cows were better (Muller et al., 2013b).

\section{Conclusion}

Since climate change is going to influence dairy production, it is important to have an improved understanding of adaptation of dairy cattle to their production environments. Descriptions of production environments are therefore vital for the meaningful evaluation of performance data and comparison of performances of genotypes. Studies and recording programmes that measure performance would require a description of the environment(s) in which the measurements are taken. Tools would therefore need to be developed to overlay climatic data sets onto the production environments to quantify them properly.

\section{Acknowledgements} study

The authors would like to thank the SA Holstein Breeders' Society for providing the data for this

\section{Authors' Contributions}

Conception and design, analyses and drafting of paper - RW; Information on dairy production systems and climate change, support with interpretation \& revision of manuscript - MMS; Sourcing of data, support with interpretation \& revision of manuscript - FWCN.

\section{Conflict of Interest Declaration}

The authors certify that they have no affiliations with or involvement in any organization or entity with any financial or non-financial interest in the subject matter or materials discussed in this manuscript.

\section{References}

Baldwin, R.A., 2009. Use of maximum entropy modeling in wildlife research. Entropy, 11:854-866.

Berman, A., Folman, Y., Kaim, M., Mamen, M., Herz, Z., Wolfenson, D., Arieli, A. \& Graber, Y., 1985. Upper critical temperatures and forced ventilation effects for high yielding dairy cows in a subtropical climate. J. Dairy Sci. 68 , 1488-1495.

Bernabucci, U., Lacetera, N., Baumgard, L.H., Rhoads, R.P., Rhonchi, B. \& Nardone, A., 2010. Metabolic and hormonal acclimation to heat stress in domesticated ruminants. Animal 4, 1167-1183.

Du Preez, J.H., Giesecke, W.H. \& Hattingh, P.J., 1990a. Heat stress in dairy cattle and other livestock under southern African conditions. I. Temperature-humidity index mean values during the four main seasons. Onderstepoort $\mathrm{J}$. Vet. Res. 57, 77-87.

Du Preez, J.H., Hattingh, P.J., Giesecke, W.H. \& Eisenberg, B.E., 1990b. Heat stress in dairy cattle and other livestock under southern African conditions. II. Identification of areas of potential heat stress during summer by means of observed true and predicted temperature-humidity index values. Onderstepoort J. Vet. Res. 57, 183-187.

Du Preez, J.H., Hattingh, P.J., Giesecke, W.H. \& Eisenberg, B.E., 1990c. Heat stress in dairy cattle and other livestock under southern African conditions. III. Monthly temperature-humidity index mean values and their significance in the performance of dairy cattle. Onderstepoort J. Vet. Res. 57, 243-248.

ESRI, 2014. ArcGIS 10.2.2. Environmental Systems Research Institute, Inc., Redlands, CA., USA.

Hahn, G.L., 1999. Dynamic responses of cattle to thermal heat load. J. Anim. Sci. 77 (Supplement 2), 10-20.

Kadzere, C.T., Murphy, M.R., Silanikove, N. \& Maltz, E., 2002. Heat stress in lactating dairy cows: A review. Livest. Prod. Sci. 77, 59-91.

McParland, S., Kearney, J.F., Rath, M. \& Berry, D.P., 2007. Inbreeding effects on milk production, calving performance, fertility, and conformation in Irish Holstein-Friesians. J. Dairy Sci. 90, $4414-4419$. 
Meissner, H.H., Scholtz, M.M. \& Palmer, A.R., 2013a. Sustainability of the South African livestock sector towards 2050 Part 1: Worth and impact of the sector. S. Afr. J. Anim. Sci. 43, 282-297.

Meissner, H.H., Scholtz, M.M. \& Engelbrecht, F.A., 2013b. Sustainability of the South African livestock sector towards 2050 Part 2: Challenges, changes and required implementations. S. Afr. J. Anim. Sci. 43, 298-319.

Muller, C.J.C., Goni, S., Dzama, K. \& Botha, J.A., 2013a. The beef production of a Jersey herd as affected by crossbreeding using Fleckvieh sires. Proc. 20th Conf. Assoc. Advmt. Anim. Breed. Genet. 21-23 October 2013. Napier, New Zealand. p. 443-446.

Muller, C.J.C., Potgieter, J.P., Cloete, S.W.P. \& Botha, J.A., 2013b. Reproductive performance of Holstein and Fleckvieh $x$ Holstein heifers and cows in a total mixed ration feeding system. Proc. 20th Conf. Assoc. Advmt. Anim. Breed. Genet. 21-23 October 2013. Napier, New Zealand. p. 439-442.

Muller, C.J.C. \& Scholtz, M.M., 2014. Ways to reduce the environmental impact of dairy farming. Appl. Anim. Husb, \& Rural Developm. 7, 31-37.

Nakićenović, N. \& Swart, R., eds, 2000. Special Report on Emissions Scenarios. A Special Report of Working Group III of the Intergovernmental Panel on Climate Change. Cambridge University Press: Cambridge. 599 pp.

Phillips, S.J. \& Dudík, M., 2008. Modeling of species distributions with Maxent: New extensions and a comprehensive evaluation. Ecography 31, 161-175.

Phillips, S.J., Dudík, M. \& Schapire, R.E., 2004. A maximum entropy approach to species distribution modeling. Proceedings of the 21st International Conference on Machine Learning, Banff, Canada.

Phillips, S.J., Dudík, M. \& Schapire, R.E., 2005. Maxent software for species distributions modelling. https://www.cs.princeton.edu/ schapire/maxent/

Phillips, S.J., Anderson, R.P. \& Schapire, R.E., 2006. Maximum entropy modelling of species geographic distributions. Ecol. Model. 190, 231-259.

Rust, J.M. \& Rust, T, 2013. Climate change and livestock production: A review with emphasis on Africa. S. Afr. J. Anim. Sci. 43, 255-267.

Salem, M.B. \& Bouraoui, R., 2009. Heat stress in Tunisia: Effects on dairy cows and potential means of alleviating it. S. Afr. J. Anim. Sci. 39, 256-259.

Scholtz, M.M., Du Toit, J. \& Neser, F.W.C, 2014. Antagonism in the carbon footprint between beef and dairy production systems. S. Afr. J. Anim. Sci. 44 (5), S17-S20.

Scholtz, M.M., Maiwashe, A., Neser, F.W.C., Theunissen, A., Olivier, W.J., Mokolobate, M.C. \& Hendriks, J., 2013. Livestock breeding for sustainability to mitigate global warming, with the emphasis on developing countries. S. Afr. J. Anim. Sci. 43, 269-281.

Schulze, R.E., 1997. South African atlas of agrohydrology and -climatology. Water Research Commission, Pretoria, South Africa.

Schulze, R.E., 2010. Atlas of climate change and the South African agricultural sector: A 2010 Perspective. Department of Agriculture, Forestry and Fisheries, Pretoria, South Africa.

Silva, R.G., 2000. Introducao a bioclimatalogia animal. Sao Paulo, Brazil, Ed. Nobel

Ward, D.F., 2007. Modelling the potential geographic distribution of invasive ant species in New Zealand. Biol. Invasions, 9: 723-735.

West, J.W., 1999. Nutritional strategies for managing the heat stressed dairy cow. J Anim Sci 77, 21-35.

West, J.W., 2003. Effects of heat stress on production in dairy cattle. J. Dairy Sci. 86, 2131-2144.

Zehetmeier, M., Baudraco, J., Hoffman, H. \& Heissenhuber, A., 2012. Does increasing milk yield per cow reduce greenhouse gas emissions? A system approach. Animal. 6, 154-166.

Zweig, M.H. \& Campbell, G., 1993. Receiver operating characteristic (ROC) plots: A fundamental evaluation tool in clinical medicine. Clin. Chem. 39 (4), 561-577. 